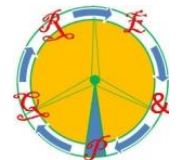

\title{
Future European energy markets and Industry 4.0 potential in energy transition towards decarbonization
}

\author{
Eva M. Urbano ${ }^{1}$, Victor Martinez-Viol ${ }^{1}$, Konstantinos Kampouropoulos ${ }^{2}$ and Luis Romeral ${ }^{1}$ \\ ${ }^{1}$ MCIA Research Center, Department of Electronic Engineering \\ Universitat Politècnica de Catalunya \\ Rambla de Sant Nebridi 22, 08222 Terrassa (Spain) \\ Phone:+34 937 98519, e-mail: eva.maria.urbano@upc.edu, victor.martinez.viol@upc.edu, luis.romeral@upc.edu \\ ${ }^{2}$ Fundació Eurecat, Centre Tecnològic \\ Plaça de la Ciència 2, 08242 Manresa (Spain) \\ Phone: +34 938777 373, e-mail: Konstantinos.kampouropoulos@eurecat.org
}

\begin{abstract}
Climate change, economic growth and fossil fuel price volatility are forcing governments and thus society to adopt economical and technical measures in the energy sector to reach sustainability. These actions can be seen as opportunities for the stakeholders that form the energy market and also for new actors that may enter as a consequence of the energy transition that is taking place. In this paper, a description of the energy targets and potential market scenarios in Europe is carried out, together with a review of the policies implemented to achieve these objectives. Within this framework, the possibility of the industry to adopt a crucial role in the development of the new energy market is also analysed. The potential tools for its achievement are also presented, together with some of the techniques and mechanisms that make it feasible. From this study, it can be concluded that the industrial sector will become a major distributed prosumer, providing services to the energy market and facilitating the energy transition towards the decarbonization of the society.
\end{abstract}

Key words. Electricity markets, flexibility, renewable energy sources, smart factories.

\section{Introduction}

Climate change has become a critical issue with worldwide implications which is taking special attention by several governments around the globe. The effects of climate change have to be stopped before they cause irreversible impacts on the environment. Global energy use has been increasing along with economic growth. As shown in [1], there is a strong relationship between energy consumption, energy prices and economic growth, concluding that economic growth tends to increase energy consumption and usually energy supply from other countries. In the European case, the external energy supply is mainly based on fossil-fuels and the incrementation in its dependence will cause vulnerability of the energy market due to the price volatility of the fossil-fuel sector [2]. Intending to reach a more secure and sustainable energy system without scarifying economic growth, it is crucial to increase energy efficiency, decrease energy use and perform a decarbonization of the society. The increase in energy efficiency and the reduction of emissions coming from the energy sector will suppose a change in the deterioration trend of the environment and a step ahead towards the self-sufficiency of energy markets.

The European Commission has already started the transition to a new energy market. Since 2000, several energy policies, subsidies and founds have been implemented to achieve the clean energy objectives stated for 2020. Regarding decarbonization, it has been possible to verify that economic growth and low-carbon transition are compatible, as it was concluded by the European Commission in [3]. The implementation of Renewable Energy Sources (RES) has also been a focus of attention during this period. In 2016, the consumption from RES represented $17 \%$ of the total consumption, approaching the $20 \%$ target for 2020 . Beyond 2020, new targets have been stated for 2030 and 2050. The main objective, decarbonization, has been set to a reduction of greenhouse gas (GHG) emissions to 80-95\% below 1990 levels for 2050 [4]. The measures implemented until now are still showing their effects and will probably continue delivering benefits past 2020. However, their advantages will not be enough to achieve 2050 targets. For this reason, new energy strategies and potential scenarios are being studied, and the impact of several measures in the energy market are being further analysed.

In this paper, a vision of these future energy markets is presented, together with an assessment of their different environmental implications. A review of the measures that are being applied or that will be available in the close future is also exposed and their real impact in the energy market studied. The target for these measures must include the industrial sector, which nowadays accounts for more than $25 \%$ of total European energy consumption [5] and will probably become a key actor in the future energy market. Therefore, the potential benefits of creating new 
energy roles in the market from industrial sites are studied in this paper, considering them as a potential source of flexibility, introducing RES in the system, increasing internal and external system efficiency and becoming a distributed prosumer.

This paper is structured as follows. Firstly, the possible main characteristics of the future energy market are drawn in Section 2. Secondly, in Section 3 the current legislation is studied together with the impacts that it causes in the energy transition. Furthermore, some solutions to the problems raised by these legislations are proposed in the same section. Thirdly, in Section 4, the potential of the industry is discussed, presented as a tool for the energy transition by applying several of the ideas shown in the previous sections. Fourthly, in Section 5 a use case is shown in which the possible behaviour of the Industry 4.0 in upcoming energy market is analysed. Lastly, in Section 6 the work's conclusions are drawn.

\section{Future energy markets scenarios}

Several strategies and measures to reach 2020 sustainable scenario have already been implemented, expecting to keep providing results past this year. According to the last European Commission report [6], the 2020 environmental and energy targets were already achieved or close to its objectives by 2016. However, these measures will not provide enough decarbonization to achieve 2050 targets, making fundamental the modernisation of the energy system. Similarly, actions related to the investment in realistic technological solutions, empowering citizens and aligning action in key areas such as the industry are necessary to reach the established goals [3]. The objective of $80-95 \%$ reduction in GHG emissions will only be possible if a major change in the market structure and the role of stakeholders and end-users is performed. Thus, the development and implementation of past-2020 strategies and measures are urgent. In [4], the potential decarbonisation scenarios that can take place in Europe during the next years are analysed. The study concludes that the decarbonization scenario is achievable, reducing also the import dependency and thus the exposure to fossil-fuel price volatility, although their implications vary depending on the followed path. Despite this fact, it is necessary to define new legal and market instruments to practically deploy these new scenarios.

The main implication and the one that is common in all the scenarios is that there will be a transition from high fuel operational costs to low fuel costs but high capital expenditure. This variation in the location of costs will force energy markets to adapt its pricing structure. It will also suppose an opportunity for industry and service providers to innovate in the generation, storage and consumption management technology. Another common implication is the electrification of the system, increasing the use of electricity despite the general decrease in carbon-based energy use. This is because electrical energy can be generated through RES on a high percentage and it will contribute to the decrease in emissions of other sectors, such as transport, heating and cooling.
Apart from these implications, the final structure of the energy and specifically the electrical market will vary depending on the predominant scenario. Two of the strategies that have been considered to decrease GHG emissions are CCS and nuclear power. By increasing the presence of CCS and nuclear power, the GHG emissions can be significantly diminished. In fact, in [7] several benefits of the commercial deployment of this technology are exposed, presenting the capability of the net removal of $\mathrm{CO} 2$ from the atmosphere. However, both nuclear power and CCS have strong negative environmental impacts. In [8], the environmental impacts of the usage of nuclear power are identified, concluding that developments for ecological safety should be performed. Regarding CCS, in [9] it is shown that it can cause acidification and human toxicity, which contributes to global warming. Moreover, the future of CCS and nuclear power crucially depends on social acceptance and, especially in the case of CCS, its viability has to be demonstrated in large scale before a $\mathrm{CO} 2$ infrastructure, which does not currently exist, is developed.

In the case that CCS and nuclear power become a restricted resource due to its collateral effects on the environment and society, the increase in the share of RES and energy efficiency of the system becomes not only advisable but essential. Storage technologies are key aspects for this to happen. However, storage is currently more expensive than other solutions such as gas backup generation. Although the need for energy efficiency solutions with renewable energy implementations is clear; the installation of ESS can be decreased if smart grids are implemented. With the inclusion of smart grids, the power system will change from a centralized structure to a decentralized and hybrid structure, allowing to decongest the transmission and distribution networks and minimize losses. A decentralized structure will only be possible if adequate infrastructure for distribution, interconnection and transmission is performed, to effectively connect the flexibility resources, including demand management, ESS, Distributed Generation (DG) and prosumers. The EU has targeted to eliminate electrical islands and to create a single integrated European energy market [10]. However, measures should assess not only transmission capacity between member countries but also connectivity in local networks and smart grids [12].

The exposed scenarios and assumptions lead to the delimitation of a future energy market in which RES, energy efficiency and smart flexible resources play a significant role. Their impact in the market due to the change in the location of the capital has to be studied and changes in the pricing mechanism and market legislation will need to be adopted.

\section{Electricity market legislation}

The primary focus of the climate and renewable energy legislation in Europe is to reduce energy import dependence and decrease environmental harm caused by the energy sector. To do so, there is a will to decrease energy consumption, increase the share of RES and reduce GHG emissions. The measures implemented to 
achieve the previously stated targets will affect not only current producers and distributors but also consumers, including industries.

The current energy market was designed, due to historical reasons, for a power system based on dispatchable energy sources. This market is based on high positive marginal costs and dispatchability of power. The nature of RES supposes a challenge for the integration of low-carbon energy sources into the market due to its main characteristics: variability and uncertainty, which produce a technical issue that still needs to be solved nowadays. There are also barriers regarding investment and cost management of RES installation. These types of installations suppose high capital and integration costs. However, the marginal costs of RES, which are the ones considered at the wholesale market, are usually close to zero [13]. These facts present an incompatibility between electricity liberalization and renewable policy, making a high share of RES not possible due to the fact that owners of RES plants would be unable to earn a return on their investment with the current energy pricing mechanisms [14]. One of the main measures adopted by the EU to increase the use of RES and decrease GHG and energy use is to actuate on the energy costs. However, a modification of the energy price based on taxes or levies to enforce policies influences negatively the competitiveness of energy-intensive sectors [15], which produces a contrary result to other targets of the EU. The legislation implemented to carry out the energy transition has to be carefully studied and analysed to avoid negative effects in the competitiveness, sustainability and security of supply of the system. It is crucial to establish climate policy using market mechanisms instead of modifying the price of the energy, and for this to happen there is a requirement to redesign the market clearing mechanism to be able to accommodate RES. The redesign should lay in the modification of the pricing structure to better capture the full renewable cost structure, as well as the incorporation of higher time resolution and later gate closure time to fit RES behaviour [16].

The previously mentioned measures would enable the incorporation of large-scale RES into the market, supporting business models for plant owners. However, a completely renewable energy scenario is not possible without accompanying RES with other capacity measures to solve intermittency issues. The electrical system should be able to adapt itself to the requirements imposed by the variability of RES, making flexibility a key requisite for a renewable-based energy system [17]. This flexibility can mean flexible generation, storage, Demand Response (DR) and interconnection. The measures that are being studied for this point, such as the deployment of smart grids, Energy Hubs (EH), Virtual Power Plants (VPP) and of conveniently distributed generation together with a more active role of the Distribution System Operator (DSO), could help not only in creating flexibility but also in improving the efficiency of the transmission and distribution systems, enabling and overall energy use without compromising the competitiveness of the system. In this sense, large, medium and small enterprises as well as the aggregations of them can play a significant role in the new scenario. Europe is clearly moving towards a market with multiple types of new actors and where interconnection and flexibility are key factors for the improvement in energy efficiency and a decrease in harmful emissions. Prosumer aggregation policies are gaining interest by Member Countries, creating communities able to extract and introduce energy to and from the utility grid at specific time intervals, overcoming the challenges introduced by RES [18].

The implemented legislation until now will need to be modified and adapted to the outlined trends, enabling the creation of smart grids, DG and prosumer entities without scarifying the competitiveness of the system. The basis for new energy trading mechanisms is also to be settled in order to enable an increase in the share of RES as well as the possibility of new actors to enter into the electrical market.

\section{Industry 4.0 in the energy transition}

The previous section described the modifications that will need to be performed in the electrical market to allocate RES, foster decarbonization and improve energy efficiency. The main streams to achieve EU targets are the creation of Smart Grids, EH, VPP, DR capabilities and prosumer actors, who are able to produce and consume energy; creating flexibility in the demand side to increase the incorporated share of RES. Until now, the focus has been the tertiary sector. However, in the EU $25 \%$ of the total energy consumption happens in the industrial sector, where programs for the incorporation of RES, DR and prosumers can also be implemented although they have still not been assessed.

The potential of the Industry 4.0 to adopt efficiency measures and decrease their environmental impact on the society should be considered when establishing the baselines for the future energy markets, as the energy consumption, energy equipment, ESS and RES present in industrial sites enable the establishment of novel energy management strategies that could take into account the state of the external market to optimize their internal operation and interaction with utility grids. Several industrial facilities account with multi-carrier energy systems coupled between them. The integration and operation of this infrastructure can be done through the creation of an EH, a novel concept which optimally links the available energy sources in an energy infrastructure [19]. The implementation of an EH in a factory leads to an increase in energy efficiency which supposes direct economic and environmental benefits for the consumer [20]. This idea can be broadened considering the external market. The first approach historically contemplated has been to adopt DR capabilities, scheduling load according to the market needs and thus creating flexibility in the electrical network. DR is added to $\mathrm{EH}$ optimization through price signals sent by the energy supplier and the results of this optimization show gains for the consumer and assistance to the electricity grid, leading to a flatter demand curve [21]. Although this strategy already demonstrates important benefits for both industry and electricity market, it does not implement the recent 
advances in legislation which enables the creation of selfconsumption communities and prosumer microgrids.

Prosumer industrial sites can be created from single manufacturing plants or through the aggregation of several entities together with close-placed RES generation. The result of this aggregation would act as a single entity in front of external energy structures, creating a VPP able to introduce energy in the utility grid when required. These new energy management strategies will lead to higher economic savings than in previous cases due to the exploitation of internal energy assets against the external market [24]. The EU has recently opened the legislation path for this solution to be implemented and Member Countries are developing policies for the inclusion of these prosumer smart grids and VPP into the energy infrastructure established [25], [26].

\section{Use case}

Industry 4.0 will be a powerful tool during the energy transition to achieve the targets that have been set by the EU. As seen in the previous section, industrial sites can integrate RES and support energy market adopting prosumer capabilities, either alone or aggregated. The objective of the use case developed in this section is to verify the economic viability of the creation of a prosumer entity out of an industrial plant, corroborating then the potential interest by manufacturing site owners to invest in the creation of VPPs. This use case is based on an automotive manufacturing plant connected to the electrical and gas energy networks with a total amount of primary energy purchased of $9.5 \mathrm{MWh}$ per month. The demand can be split into electrical and thermal, and the conversion equipment of the plant is formed by a boiler and a cogeneration plant, which interconnects the electrical and the thermal sides of the energy structure. As an example of the economic viability of the implementation of prosumer capabilities, two days are studied in this section. To implement a smart energy management system able to decide when to share energy with the utility grid and when to store it, there is a requirement to implement RES and ESS systems. A Photovoltaic (PV) system is selected as the RES to be implemented in the factory, which will cover an available space of $15000 \mathrm{~m}^{2}$, and the ESS is sized to supply energy to critical loads during a predefined interval of time. With this information, the comparison between electrical load and energy generated by the PV system for the studied days can be seen in Fig. 1 and Fig. 2. The electricity price at the wholesale energy market has also been added to the graphs to visualize the potential benefits of including the PV system together with an ESS for external market purposes.

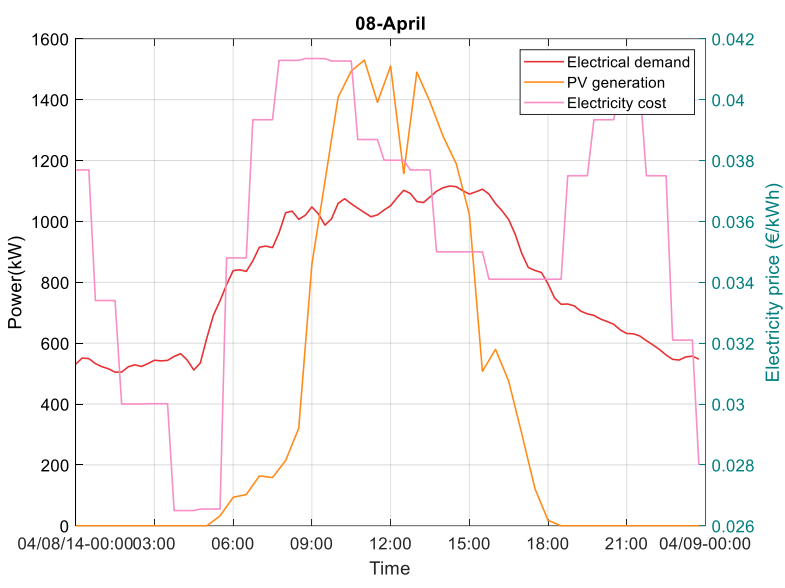

Fig. 1: Electricity cost and electrical load and generation for the 8th of April of 2014.

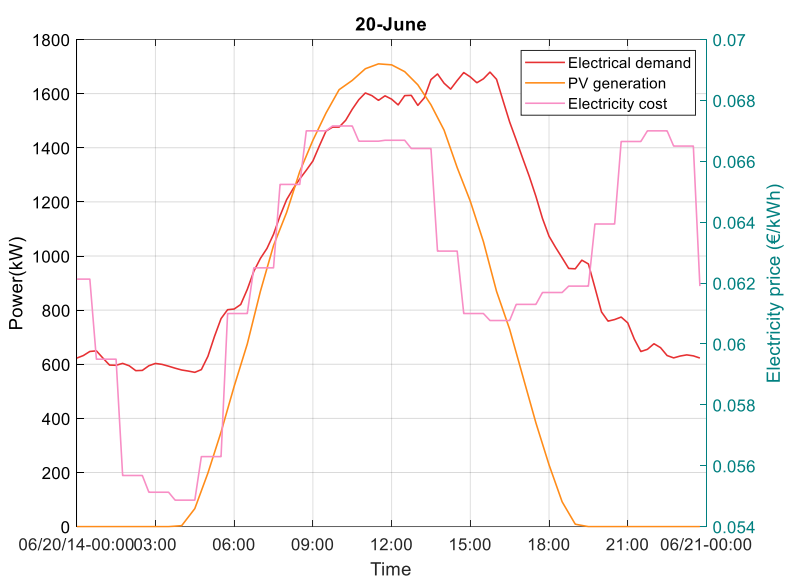

Fig. 2: Electricity cost and electrical load and generation for the 20th of September of 2014.

It can be seen that in both cases, the energy generated by the PV system overcomes the electrical load of the system at some time intervals, although these do not necessarily coincide with the time intervals at which the electricity cost is higher. Until now, the energy generated by the PV system in factories has been used internally or sold directly in its totality. However, with the arise of selfconsumption legislations that enable prosumer capabilities, the energy management system can buy or sell electricity depending on their operation points and the state of the external market. An optimization is performed taking into account this last approach in which the installation, operation and maintenance costs of energy equipment are considered, together with the possibility to exchange energy with the utility grid. An evolutionarybased optimization algorithm has been tuned to obtain the maximum benefit from internal energy flow and external energy trading. The results of the optimization for the first day can be seen in the following figures. 


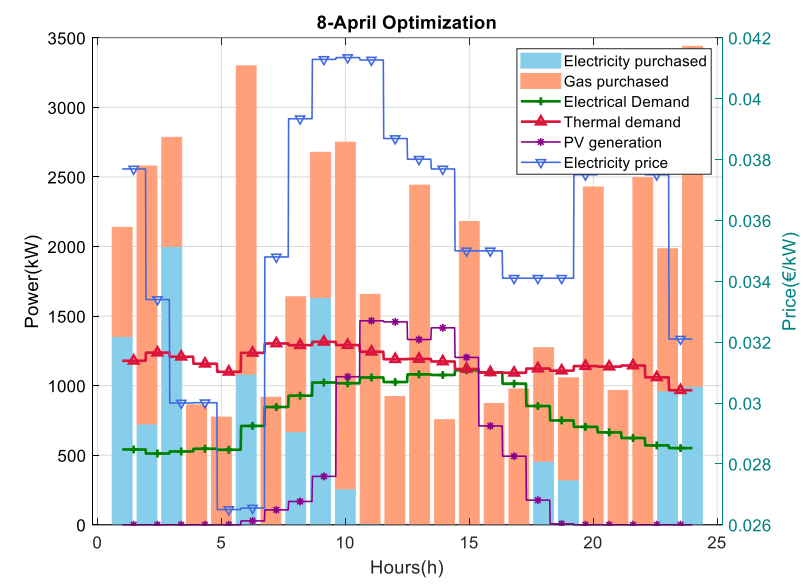

Fig. 3: Optimization for the 8th of April of 2014 showing the energy purchased.

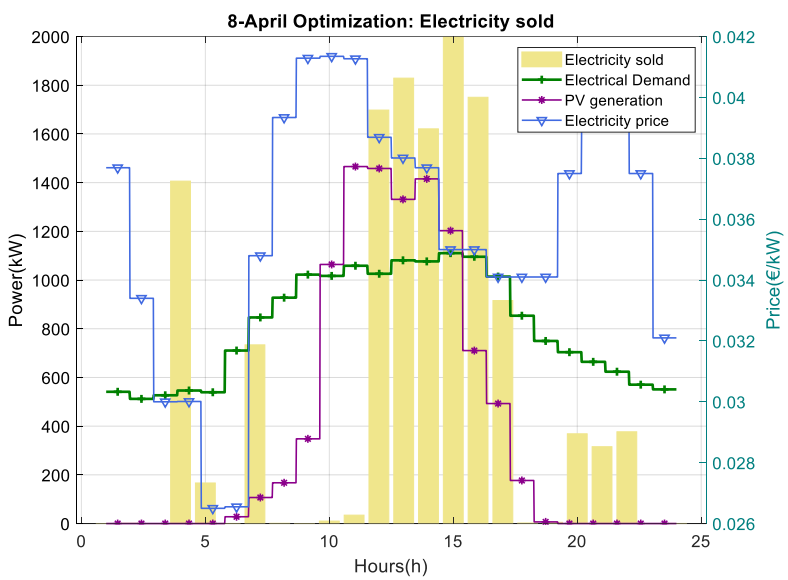

Fig. 4: Optimization for the 8th of April of 2014 showing the energy sold.

In Fig. 3 is possible to appreciate that between $11 \mathrm{~h}$ and $17 \mathrm{~h}$ is when the energy cost is high and electrical energy is not being purchased. It is also detectable that gas is being bought at a higher rate than the needed to fulfil electrical demand due to the existence of a cogeneration plant which operates close to its maximum power capability and generates electricity to be consumed or stored at the electrical side of the factory. The prosumer behaviour of the factory can be seen in Fig. 4. Here it appears that what happened between $11 \mathrm{~h}$ and $17 \mathrm{~h}$ is that electricity is being sold taking profit from its high value. For the second day under study, the results can be observed in Fig. 5 and Fig. 6.

The same type of behaviour is detectable in this case. During the hours of the maximum price at the wholesale market, the optimal decision is to sell electricity to the utility grid instead of purchasing it.

Table I: Economic running cost of the factory

\begin{tabular}{|l|c|c|c|}
\hline Day & $\begin{array}{l}\text { Prosumer } \\
\text { operation }\end{array}$ & $\begin{array}{l}\text { Standard } \\
\text { operation }\end{array}$ & $\begin{array}{l}\text { Economic } \\
\text { savings }\end{array}$ \\
\hline $\begin{array}{l}8^{\text {th }} \\
2014\end{array}$ & $6680 €$ & $9300 €$ & $2620 €$ \\
\hline $\begin{array}{l}20^{\text {th }} \text { June } \\
2014\end{array}$ & $6200 €$ & $8700 €$ & $2500 €$ \\
\hline
\end{tabular}

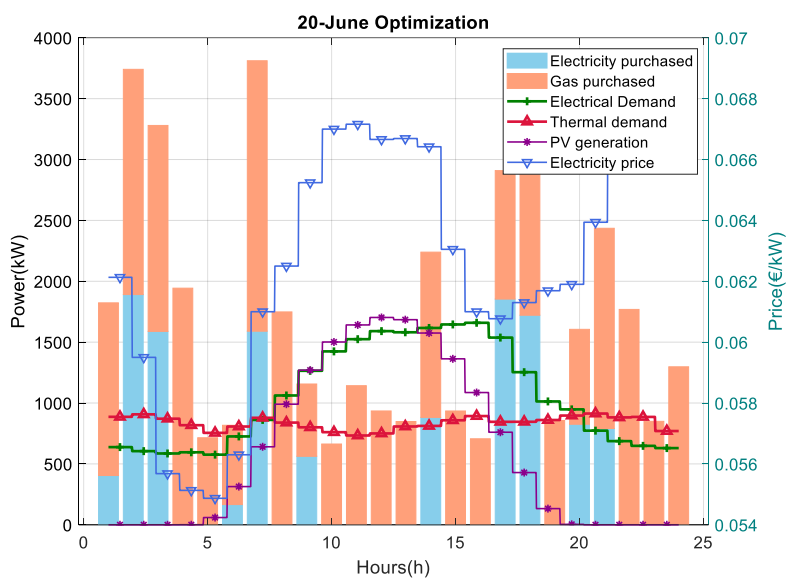

Fig. 5: Optimization for the 20th of September showing the energy purchased.

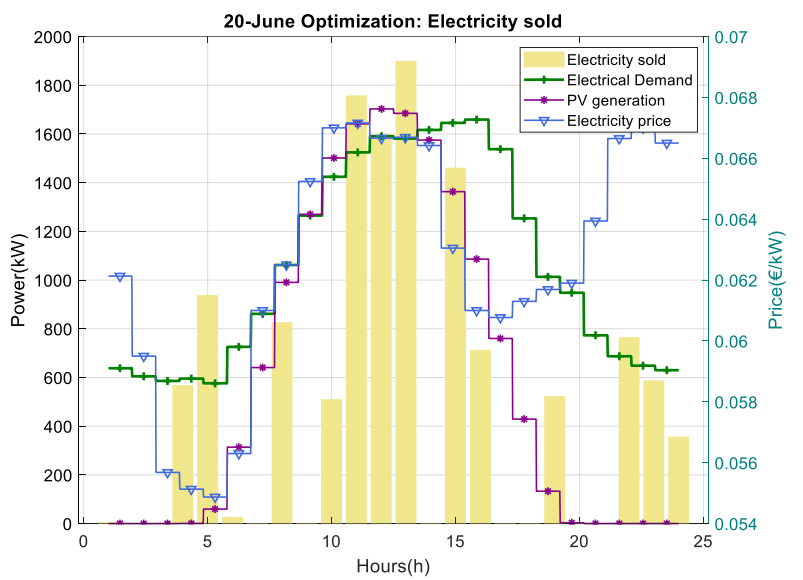

Fig. 6: Optimization for the 20th of April showing the energy sold.

In Fig. 7 it appears that the electricity being sold is higher than the generated by the PV system during the time interval between $11 \mathrm{~h}$ and $14 \mathrm{~h}$. This means that other source of electrical power, such as the cogeneration system and the ESS, are being used to fulfil the electrical demand and also to increase the amount of energy sold to the utility grid.

In order to check the economic viability of performing as a prosumer, an optimization has been carried out with the same manufacturing plant but without enabling the option to trade energy with the utility grid or adopt demand response measures. By applying a prosumer behaviour and its related technology, the final cost of energy use including the amortization of energy equipment is lower than the cost for a standard manufacturing plant. These costs can be seen in Table I, together with the savings obtained.

In this section it has been shown that there is a possibility to trade energy with the utility grid, by controlling the operation points of the energy equipment to profit from the state of the external energy market, introducing green energy to the external infrastructure when demand and electricity cost is high. Due to its economic viability, this energy management strategy can be added to the current existing business models of manufacturing plants, enabling the creation of a huge number of prosumer 
industrial sites promoting the decentralization of the electrical grid.

\section{Conclusions}

In this paper, the energy targets, potential market scenarios and energy legislation in Europe has been reviewed showing a clear trend towards the inclusion of RES and flexibility sources. The policies implemented until now and the ones presented as a draft enable the possibility to create aggregated entities, smart grids, energy hubs and demand-responsive consumers. Within this framework, the capacity of the industry to adopt a crucial role in the development of the new energy has been analysing by showing its ability to create prosumer aggregated entities exploiting its internal energy equipment for market purposes. The use case developed has shown the economic viability of this strategy as well as the benefit that the utility grid can obtain from the energy transactions performed. With these results, it can be said that the energy prosumer will become a key actor during the energy transition and economy decarbonization and that industries are suitable to adopt this role as they present a complex and smart energy infrastructure with high energy transactions potential.

\section{Acknowledgements}

The authors would like to thank the support provided by the Catalan Agency for Management of University under the grant 2017 SGR 967.

\section{References}

[1] G. Tariq, H. Sun, M. Haris, and Et.al., "Energy Consumption and Economic Growth: Evidence from Four Developing Countries," Am. J. Multidiscip. Res., vol. 7 , no. $1,2018$.

[2] S. C. Bhattacharyya, "Fossil-fuel dependence and vulnerability of electricity generation: Case of selected European countries," Energy Policy, vol. 37, no. 6, pp. 2411-2420, 2009.

[3] European Commission, "Reflection Paper - Towards a Sustainable Europe By 2030," 2019.

[4] European Commission, "Roadmap 2050," 2011.

[5] Y. Chan and R. Kantamaneni, "Study on Energy Efficiency and Energy Saving Potential in Industry and on Possible Policy Mechanisms.” 2015.

[6] Eurostat, Smarter, greener, more inclusive? 2018.

[7] M. Bui et al., "Carbon capture and storage (CCS): The way forward," Energy Environ. Sci., vol. 11, no. 5, pp. 1062-1176, 2018.

[8] B. F. Myasoedov and S. N. Kalmykov, "Nuclear power industry and the environment," Mendeleev Commun., vol. 25 , no. 5, pp. 319-328, 2015.

[9] R. M. Cuéllar-Franca and A. Azapagic, "Carbon capture, storage and utilisation technologies: A critical analysis and comparison of their life cycle environmental impacts," J. CO2 Util., vol. 9, pp. 82$102,2015$.

[10] Red Eléctrica de España (REE), "Electricity interconnections: a step forward towards a single integrated European energy market," 2012.

[11] P. Zhou, J. Ye, W. Chen, L. Zhao, and M. Zeng, "Research on European Union Transnational Electricity
Market Construction and Renewable Energy Transaction Mechanism," IOP Conf. Ser. Earth Environ. Sci., vol. 170, no. 4, 2018.

F. Lopes and H. Coelho, Electricity Markets with Increasing Levels of Renewable Generation: Structure, Operation, Agent-based Simulation, and Emerging Designs. 2018.

[13] H. Lo, S. Blumsack, P. Hines, and S. Meyn, "Electricity rates for the zero marginal cost grid," Electr. J., vol. 32, no. 3, pp. 39-43, 2019.

[14] J. Blazquez, R. Fuentes-Bracamontes, C. A. Bollino, and N. Nezamuddin, "The renewable energy policy Paradox," Renew. Sustain. Energy Rev., vol. 82, no. September 2017, pp. 1-5, 2018.

[15] M. T. Costa-Campi, J. García-Quevedo, and E. TrujilloBaute, "Electricity regulation and economic growth," Energy Policy, vol. 113, no. June 2017, pp. 232-238, 2018.

[16] J. Hu, R. Harmsen, W. Crijns-Graus, E. Worrell, and M. van den Broek, "Identifying barriers to large-scale integration of variable renewable electricity into the electricity market: A literature review of market design," Renew. Sustain. Energy Rev., vol. 81, no. September 2016, pp. 2181-2195, 2018.

[17] R. A. Verzijlbergh, L. J. De Vries, G. P. J. Dijkema, and P. M. Herder, "Institutional challenges caused by the integration of renewable energy sources in the European electricity sector," Renew. Sustain. Energy Rev., vol. 75, no. October 2016, pp. 660-667, 2017.

[18] R. Moura and M. C. Brito, "Prosumer aggregation policies, country experience and business models," Energy Policy, vol. 132, no. June, pp. 820-830, 2019.

[19] K. Kampouropoulos, F. Andrade, E. Sala, A. G. Espinosa, and L. Romeral, "Multiobjective optimization of multi-carrier energy system using a combination of ANFIS and genetic algorithms," IEEE Trans. Smart Grid, vol. 9, no. 3, pp. 2276-2283, 2018.

[20] M. Geidl and G. Andersson, "Optimal coupling of energy infrastructures," 2007 IEEE Lausanne POWERTECH, Proc., pp. 1398-1403, 2007.

[21] M. Salehimaleh, A. Akbarimajd, K. Valipour, and A. Dejamkhooy, "Generalized modeling and optimal management of energy hub based electricity, heat and cooling demands," Energy, vol. 159, pp. 669-685, 2018.

[22] S. Cui, Y. W. Wang, J. W. Xiao, and N. Liu, "A TwoStage Robust Energy Sharing Management for Prosumer Microgrid," IEEE Trans. Ind. Informatics, vol. 15, no. 5, pp. 2741-2752, 2019.

[23] N. Liu, M. Cheng, X. Yu, J. Zhong, and J. Lei, "Energy-Sharing Provider for PV Prosumer Clusters: A Hybrid Approach Using Stochastic Programming and Stackelberg Game," IEEE Trans. Ind. Electron., vol. 65, no. 8, pp. 6740-6750, 2018.

[24] E. M. Urbano, V. Martinez-Viol, and L. Romeral, "Optimization of industrial plants for exploiting energy assets and energy trading," in 24th IEEE International Conference on Emerging Technologies and Factory Automation (ETFA), 2019, vol. 1, pp. 1805-1812.

[25] N. Šajn, "Briefing EPRS: Electricity 'Prosumers' European Parliamentary Research Service," no. Briefing Novemeber 2016. pp. 1-10, 2016.

[26] E. y T. Ministerio de Industria, "Real Decreto $244 / 2019$, de 5 de abril, por el que se regulan las condiciones administrativas, técnicas y económicas del autoconsumo de energía eléctrica," pp. 690-695, 2019. 